\title{
Editorial: Socio-Scientific Issues and Education for Sustainability in Contemporary Education
}

\author{
Ian Robottom • Laurence Simonneaux
}

Published online: 9 September 2011

(C) Springer Science+Business Media B.V. 2011

This Special Issue of Research in Science Education (RISE) focuses on the role of the use of socio-scientific issues in science education within the context of the United Nations Decade for Education for Sustainable Development that runs from 2005 to 2014 (Unesco 2003). Papers in this issue describe and assess critically some ways in which the pedagogical approach of basing curriculum around investigations of naturally-occurring socio-scientific issues may attend to both the interests of science education and the newer and highly visible educational discourse of Education for Sustainability (EfS). Speaking at the international launch of DESD in New York in March 2005, UNESCO Director General Koichiro Matsuura set out a clear challenge for ESD:

The ultimate goal of the Decade is that education for sustainable development is more than just a slogan. It must be a concrete reality for all of us - individuals, organizations, governments - in all our daily decisions and actions, so as to promise a sustainable planet and a safer world to our children, our grandchildren and their descendants... Education will have to change so that it addresses the social, economic, cultural and environmental problems that we face in the 21 st century (Unesco, 2005, p. 2).

This Special Issue of RISE explores ways in which science education itself may 'change so that it addresses the social, economic, cultural and environmental problems we face in the 21 st century'. In this sense, this Special Issue addresses a contemporary challenge for the field of science education and therefore research in science education.

In exploring the role of socio-scientific issues (SSIs) in responding to this challenge, the authors in this Special Issue do not follow nor prescribe any specific approach; on the contrary a feature of this set of articles as a whole is their diversity around the common SSI theme. While agreeing that SSIs are crucial in education because scientific expertise continues to be highly regarded in society, the articles place differing emphases on their conceptualisation of ways in which education may successfully engage with biotechnology,

I. Robottom $(\bowtie) \cdot$ L. Simonneaux

Deakin University, Geelong, Australia

e-mail: ian.robottom@deakin.edu.au 
nanotechnology, animal diseases transmissible to human beings, food security, climate change, nuclear power, water management, impacts of agronomy practices, "real life" issues of relevance to the survival of specific communities and/or related to technology or technoscience education.

In a sense, while exploring the intersections of science, society, environment and sustainability within educational contexts, the large-scale tension being explored is that between commitment to the interests of disciplinary science and commitment to the interests of sustainable communities. This tension poses a delicate challenge for teachers and teacher educators - a challenge that is fundamentally epistemological in nature. Employing SSIs in science education within a context of EFS inevitably requires the taking of a position on the primacy of the classic borders of the disciplines (in this case, principally the discipline of science). Can the disciplines of the sciences, by virtue of their allegedly special epistemological characteristics of objectivity, rationality and truth, lay claim to a principal role in addressing and resolving SSIs, and does this entail a primacy for science education in EFS?

In terms of the process adopted in preparing this Special Issue, seven international authors were invited to contribute an article on their perspective on the role of SSIs in Educational for Sustainable Development; each has expertise in science education and/or Education for Sustainability and possesses a research interest in the pedagogical approach of basing curriculum on socio-scientific issues. In addition, two prominent researchers in science education were invited to provide independent commentaries on the collection of seven articles in terms of their contribution to the field of science education. As a collection, the papers in this Special Issue derived from research conducted in Australia, Canada, France, Spain and the USA. Thus the resulting collection of seven articles and two commentaries reflects the diversity of the backgrounds of the authors, the diversity of the field and the nascent nature of research and experience on the role of SSIs in science education.

Beatriz Bravo-Torija and Maria-Pilar Jimenez-Aleixandre, both of the University of Santiago de Compostela in Spain, examine studies in year 10 classrooms of a specific socio-scientific issue - that of marine resource management in an article entitled 'Progression in complexity: contextualizing sustainable marine resources management in a 10th grade classroom'. Direct classroom observation (including video- and audio-taping) was used to follow students' reasoning as they developed ecological models for managing a specific aspect of marine resources in a way that would provide continuous sustenance to a small community.

The paper prepared by Louisa Tomas and Stephen Ritchie (respectively of James Cook University and Queensland University of Technology in Australia) is entitled 'Positive Emotional Responses to Hybridised Writing about a Socio-scientific issue', and addresses the effect of engagement in an on-line study of socio-scientific issues on the emotional arousal of participating students. The research revealed that pride, strength, determination, interest and alertness were among the positive emotions most strongly elicited by this pedagogical approach, which is likely to have application in the use of socio-scientific issues within an EFS context.

The Unites States team of Michelle Klosterman (of Wake Forest University) and Troy Sadler and Julie Brown (of the University of Florida) present an article entitled 'Science Teachers' Use of Mass Media to Address Socio-scientific and Sustainability Issues'. They assert that mass media report extensively on scientific developments, and that classroom teachers of science in turn make use of media reports on science in their teaching of socioscientific and sustainability issues. The authors present a account of research on the use of 
this approach in classrooms and advance suggestions for a greater exploitation of the potential of mass media reporting of science in the educative exploration of socio-scientific and sustainability issues.

Jean Simonneaux and Laurence Simonneaux are researchers located at the Ecole Nationale de Formation Agronomique (ENFA), in Toulouse, France. In their article entitled 'Educational configurations for teaching environmental socio-scientific issues within the perspective of sustainability', they begin by pointing out that Education for Sustainability has become a mandated component of the curriculum of many countries. They present a conceptual framework for employing socio-scientific issues (they refer to socially-acute questions) within EFS curricula. This extensive conceptual frame comprises several dimensions: attributes of knowledge; epistemological assumptions of teachers; and a range of pedagogical approaches - in other words, both the substantive content and the theory and practice of teaching that content.

Ian Robottom of Deakin University in Australia in his article 'Socio-scientific issues in education: innovative practices and contending epistemologies' also asserts that socio-scientific issues consist in contests among dissenting social, economic and environmental perspectives that rarely all align, giving rise to debates whose resolution is not amenable to solely scientific approaches. Socio-scientific issues, then, exist at the intersection of differing human interests, values and motivations and are therefore necessarily socially-constructed. He considers some instances of educational practices in engaging socio-scientific issues, then considers some of the implications for professional development and research.

Jean-Marc Lange of the University de Rouen is a key figure in France in Education for Sustainability. His article in this Special Issue, entitled 'Education in sustainable development: how can science education contribute to the vulnerability perception?' adopts a different perspective on the primacy of (scientific) disciplinary work in the study of socio-scientific issues within EFS, which he sees as political contests among different interest groups in specific communities. He explores a 'prospective scenarios' approach of risk analysis in the educational engagement of the notion of 'vulnerability' in sustainability issues.

The paper of Larry Bencze, Erin Sperling and Lyn Carter of the Ontario Institute for Studies in Education, Ontario, Canada is entitled 'Students' Research-informed Socioscientific Activism: Re/Visions for a Sustainable Future'. The paper addresses the issue of student-led research into socio-scientific issues as a means of promoting environmental activism among young people.

As a collection, these seven articles present accounts of practice suggestive of a diversity of interpretations of the concept of socio-scientific issues and their use in education. The overarching perspective adopted in the independent commentaries of Russell Tytler (Deakin University) and Vaughan Prain (LaTrobe University of Bendigo) allows a comparison of similarities and differences among these diverse accounts in such aspects as:

- the purposes and curriculum framing the SSIs as interventions in science education and EFS;

- the pedagogies that underpin the interventions;

- their respective epistemologies, and the tensions between these and the epistemology of traditional science education.

- the diversity of perspectives around the confluence of thinking about school science, SSIs, and EFS;

- the challenge that the 'SSI agenda' represents to school science education's fundamental rationale, goals, learning objectives, methods and approaches to research; 
- the role that science could and should play in classroom-based investigations of SSIs where this form of inquiry is employed with a science education environment, and whether this role could or should change if SSIs are used in an EFS environment. To put this another way, whether the relative importance of the 'science discipline' vis-àvis 'the socio-scientific issue' in shaping the curriculum is qualitatively different in an EFS environment;

- the different criteria that may be employed in assessing the quality of the more applied form of curricula resulting from the use of SSIs in an EFS environment;

- $\quad$ whether the approach of employing SSIs as the focus of student inquiry necessarily entails a form of student activism; and

- the need for further research into the processes that shape and constrain 'the SSI agenda'.

Fundamentally these papers occupy a range of positions on a continuum regarding the role of socio-scientific issues in Education for Sustainability. Ultimately the issue may well be the epistemological struggle between science discipline-based interests and interests associated with sustainable communities; put another way, between placing a primacy (in curriculum and pedagogy) on teaching scientific knowledge and processes versus placing a primacy on educating about the structure and processes of sustainability issues and their resolution in specific community contexts. Tytler (in his commentary later in this issue) proposes that "...there seems to be general acceptance that the epistemic approaches of science represent the "best game in town'". The question implied in the diversity of approaches in this issue is whether this is the case in the EFS environment. While the epistemic approaches of science may well be regarded as 'the best game in town', an issue is whether, on their own, they are best suited to afford the organising framework for an adequate exploration of SSIs. In a context requiring multiple epistemological perspectives to do justice to a given SSI, such an assertion of epistemological primacy may serve to marginalise the equally necessary non-scientific perspectives required to do justice to the issue. The issue remains: in EFS, is the purpose of SSIs to improve scientific understanding, or is it to improve an understanding of sustainability issues with a view to advancing the cause of sustainable communities?

We invite readers to identify these differing positions and consider critically how socioscientific issues may play a role in their own EFS curricula.

\section{References}

UNESCO. (2003). United Nations Decade of Education for Sustainable Development (2005-2014): Framework for the International Implementation Scheme. Paris: UNESCO.

UNESCO. (2005). Initiating the United Nations Decade of Education for Sustainable Development in Australia. Report of a National Symposium. Paris: Australian National Commission for UNESCO. 